Till 5.50 the sun remained partially eclipsed. Thus we observed the sun on our steamer Ofoden, while returning to Bodö. But who could imagine our surprise, and the increase in our gratitude for the splendid conditions in which we had seen the eclipse, when, twenty minutes after totality was over, we saw the sky everywhere, and especially also at the sun's side, covered with heavy clouds! It was as if these clouds had been caused by some cooling effect of the eclipse. A. BRESTER, JR.

Delft, Holland, August 23.

\section{Air Temperature during the Solar Eclipse.}

Some observations of air temperature, which I was able to make at Vadsö during the solar eclipse on August 9, are perhaps worthy of being put on record. I observed on the plateau or flat-topped hill north of the town of Vadsö, a few minutes' walk beyond Prof. Copeland's station, and at the height of 400 feet above the sea, by aneroid. None of the astronomical observers occupied quite such a high position. It was chosen in order to escape the disturbing effect of air-currents on the hill-side sloping to the fjord. The thermometer was provided with a small bulb, and hung from the tripod of a 3 -inch telescope, the bulb being about 18 inches from the ground. No special precautions were taken to shield it from the sun's rays; un. fortunately, they were not necessary. A light northerly breeze was blowing, and the sky was heavily clouded.

Speaking roughly, the eclipse began at 4 , was total at 5 , and was over by 6 o'clock. At 4.8 and at 4.18 the temperature was $440^{\circ} \mathrm{F}$; ; at 4.23 , it was $43.5^{\circ}$; at 4.28 and $4.33,43^{\circ} 2^{\circ}$. From 4.35 to 4.43 the sun was shining brightly, and the temperature rose to $43.3^{\circ}$; at 4.53 and 4.59 , glimpses of the sun were caught before and after totality. The temperature from 4.48 to 4.58 was steady at $43^{\circ} 0^{\circ}$; at 5.0 , it had dropped to $42.1^{\circ}$; from 5.3 to 5 . 13 it stood at $42 \cdot 3^{\circ}$. By 5.33 it had risen to $43^{\circ} 8^{\circ}$, and at 5.48 , when I ceased observing, to $45^{\circ} 0^{\circ}$.

The suddenness of the fall at, or rather immediately after, totality is very marked, the depression amounting altogether to I. $9^{\circ} \mathrm{F}$. from the commencement of the eclipse, and the subsequent rise being equal to $29^{\circ} \mathrm{F}$. to the end of the eclipse.

I Savile Row, W., August 24. Hugh Rober'T Mill.

\section{The Position of Science at Oxford.}

Youk correspondent "W. E. P." shows a curious ability for injuring his own side. He says that "Oxford collectively has done her best to remove any inferiority she may have had in the past" in respect of her scientific school, and further, "it would be difficult to name a body better qualified to decide what is a good general education than Convocation itself." And yet the whole tone of his letter is a practical confession that Oxford has failed in her best attempt, and that her view of general education has resulted in a practical failure to forward an essential branch of general education. The fact is Oxford's best is bad, and her ideal education is one-sided. The most serious cause of complaint of modern society against the old universities is that they have so controlled the education of the wealthy classes of the community that the landed and professional classes have been educated apart from the commercial and industrial classes to the very great injury of both. One might as well consult a committee of clergy as to the best education for a doctor, as advise with university dons as to the best education for the general community. The influence of a Pagan civilisation has created in them an ideal of life founded on contemplative learn ing, rather than on a Christian benevolent activity.

Trinity College, Dublin, August 19. Geo. Fras. Fitzgerald.

\section{On the Notation of Terrestrial Magnetic Quantities.}

$A T$ the International Meteorological Congress to be held in Paris, a number of questions of special interest to magneticians have been proposed for discussion, among which is the following :- "The same notation should be generally employed, $I I$ for horizontal force, $X$ for the northern component, $Y$ for the western component, $Z$ for the vertical force, and $V$ for the potential." As the need of some uniform notation has been made apparent to me in connection with the journal Terrestrial Magnetism, I have been paying this matter some attention with the

NO. I 400, VOL. 547 view of obtaining a concise and logical system for adoption in that journal

The principle upon which I proceed is to take the first letter of a word designating a particular quantity, if at the same time it conforms with typographic requirements, such, for example, as declination, which is common to several languages. In this way I have thus far obtained the following : $D$ for declination, $I$ for inclination, $H$ for horizontal component of force, $V$ for vertical component, $F$ for total force. Upon examination it will be found that these letters stand for words derived, in almost all cases, originally from the Latin and Greek languages, and with but insignificant variations in spelling, common to several of the main modern languages.

The Germans will be asked to yield a point with regard to $F$, but this, as will be seen below, will be made up to them in the adoption of $G$ for magnetic potential. $V$ taken from the Latin vis, or I from intensitas, or $D$ from the Greek word $\delta \dot{v} \nu a \mu t s$, would not do for force, as they are already taken. Nor would $T$ from totus or $P$ from $\pi \hat{s} s$ answer, since the former is frequently used for time of vibration, and so in fact is the letter $P$, which stands besides for the first deflection coefficient. As I hope to be able to find a satisfactory notation for all the principal magnetic quantities, I am keeping this matter constantly in mind in adopting any particular letter. The English and French have force, and I have, therefore, adopted $F$ for total force. As it is frequently the custom to designate angular quantities by Greek letters, I should have preferred, had it been possible, to adopt $\delta$ and $\iota$ instead of $D$ and $I$, but the Greek $\iota$ is a very unsatisfactory letter from a typographical standpoint. Moreover, if found desirable later on, the small letters $d$ and $i$ or $\delta$ and $\iota$ can be reserved for the variations on the mean of day and on the mean of year respectively.

I think it very much to be deplored if $Z$, as above proposed, be universally adopted to designate the vertical force. It should not be forgotten that the Gaussian mode of resolving the magnetic force into northerly component $(X)$, westerly component $(X)$, and vertical component $(Z)$, applies to a local system of $\mathrm{co}$ ordinates, not to a fixed system, as the layman might naturally suppose-a fact which is even apparently forgotten at times by magneticians. The mean values of these components for a complete circuit of the earth along a parallel of latitude can, in consequence, no more be physically interpreted than the mean $H$, for example. I am, therefore, opposed to adopting for the vertical force a letter which in no way gives evidence of the exact quantity for which it stands. $V$, on the other hand, is logically connected with $H$, and at the same time implies that the direction of the quantity that it symbolises is local, the direction of the vertical or plumb-line varying from point to point.

For the same reasons I am not in favour of adopting $X$ for northerly component, and $Y$ for westerly component. Let authors choose this method of notation, if they prefer it ; but in a system suggested for universal adoption, it would seem to me that $N$ and $W$ would more satisfactorily meet the requirements, clearly indicating to the eye as they do the local character of the system of coordinates employed.

As a letter to designate the earth's magnetic potential, I believe none more fitting could be adopted than $G$, after Gauss, the author of this function. Gauss himself used $V$, but this letter is not sufficiently characteristic ; it is used to designate many other functions in mathematical physics; and there would, moreover, be a conflict in our system, since $V$ seems the most logical letter to designate the vertical force. L. A. BAUER.

Linden, Montgomery County, Maryland, August Io.

\section{On "Hullite."}

THE authors of a paper just published in the Transactions of the Royal Irish Academy, which is certain to be widely read, have dealt at length with the material called "hullite," urging that it is, in reality, " a hydrous glass of Jow specific gravity."

This paper was read on June I0, 1895, but a "note added in press" concludes as follows :-

"An abstract of this paper was published in Nature of Tune 27,1895 ; since then $\mathrm{I}$ have received, by the kindness of Prof. Cole, a paper by him on 'hullite' [reference given, Proc. Belfast Nat. Field Chub, $1894-5$, p. I]. It contains an interest. ing résumé of the literature of the subject, and describes, quite independently, the occurrence of 'hullite' as 'a true ground-

1 The initial letter of the German word Kraft is frequently used to designate the moment of inertia, and hence will not answer for force. 